\title{
Hydrogenation of Ethanol-Lignin of Larch Wood in Supercritical Ethanol in the Presence of Sulfated Catalysts $\mathrm{ZrO}_{2}$ and $\mathrm{Pt} / \mathrm{ZrO}_{2}$
}

Victor I. Sharypov*a,b, Natalia G. Beregovtsova ${ }^{a}$, Sergei V. Baryshnikova, Angelina V. Miroshnikova ${ }^{a}$, Oxana P. Taran ${ }^{a, b}$, Alexandr V. Lavrenov and Boris N. Kuznetsov ${ }^{\mathrm{a}}{ }^{\mathrm{a}} \mathrm{b}$ Institute of Chemistry and Chemical Technology SB RAS FRC "Krasnoyarsk Science Center SB RAS" 50/24 Akademgorodok, Krasnoyarsk, 660036, Russia ${ }^{b}$ Siberian Federal University

79 Svobodny, Krasnoyarsk, 660041, Russia 'Institute of Hydrocarbons Processing SB RAS 2, $5^{\text {th }}$ Kordnaya, Omsk, 644040, Russia

Received 16.10.2018, received in revised form 24.11.2018, accepted 07.12.2018

The process of hydrogenation of larch ethanol-lignin in supercritical ethanol in the presence of sulfated catalysts $-\mathrm{ZrO}_{2}$ and $1 \% \mathrm{Pt} / \mathrm{ZrO} \mathrm{O}_{2}$ was investigated at 250 and $300{ }^{\circ} \mathrm{C}$.

The maximum conversion of ethanol-lignin (99,5 wt. \%) and yield of liquid products (87,8 wt. \%) were obtained in the presence of bifunctional catalyst $\mathrm{Pt} / \mathrm{ZrO} \mathrm{O}_{2}$ at temperature $300^{\circ} \mathrm{C}$. Catalysts $\mathrm{ZrO} \mathrm{O}_{2}$ and Pt/ $\mathrm{ZrO}_{2}$ decrease of $\mathrm{O} / \mathrm{C}$ and $\mathrm{H} / \mathrm{C}$ atomic ratio in liquid products and increase by 2,2-2,4 times the yield of carbon oxides and methane increases as a results of intensification of deoxygenation reactions.

Keywords: larch ethanol-lignin, hydrogenation, supercritical ethanol, sulfated catalysts, $\mathrm{ZrO}_{2}$, $1 \mathrm{Pt} / \mathrm{ZrO}$, products, liquid, gaseous. 


\title{
Гидрирование этаноллигнина древесины лиственницы \\ в среде сверхкритического этанола в присутствии сульфатированных катализаторов $\mathrm{ZrO}_{2}$ и $\mathrm{Pt} / \mathrm{ZrO}_{2}$
}

\author{
В.И. Шарыпов ${ }^{\mathrm{a}, \boldsymbol{\sigma}}$, Н.Г. Береговцова ${ }^{\mathrm{a}}$, \\ С.В. Барышников ${ }^{a}$, А.В. Мирошникова ${ }^{a}$, \\ О.П. Таран ${ }^{\mathrm{a}, \tilde{\sigma}}$, А.В. Лавренов ${ }^{\mathrm{B}}$, Б.Н. Кузнецов ${ }^{\mathrm{a}, \tilde{\sigma}}$ \\ ${ }^{a}$ Институт химии и химической технологии СО РАН \\ ФИЦ «Красноярский научный центр СО РАН» \\ Россия, 660036, Красноярск, Академгородок, 50/24 \\ ${ }^{6}$ Сибирский федеральный университет \\ Россия, 660041, Красноярск, пр. Свободный, 79 \\ ${ }^{8}$ Институт проблем переработки углеводородов СО РАН \\ Россия, 644040, Омск, 5-я Кордная, 2
}

Исследован прочесс гидрирования этаноллигнина лиственницы в среде сверхкритического этанола при температурах 250 и $300{ }^{\circ} \mathrm{C}$ в присутствии сульфатированных катализаторов $\mathrm{ZrO}_{2}$ u $\mathrm{Pt} / \mathrm{ZrO}$.

Максимальные значения конверсии этаноллигнина (99,6 мас.\%) и выхода жидких продуктов (87,8 мас.\%) получены при температуре $300{ }^{\circ} \mathrm{C}$ в присутствии бифункционального катализатора $\mathrm{Pt} / \mathrm{ZrO} \mathrm{O}_{2}$. Катализаторы $\mathrm{ZrO}_{2}$ и $\mathrm{Pt} / \mathrm{ZrO} \mathrm{O}_{2}$ снижают атомные отношения $\mathrm{O} / \mathrm{C} u$ Н/С в образующихся жидких продуктах и увеличивают в 2,2 - 2,4 раза выход оксидов углерода и метана в результате интенсификации реакции деоксигенаџии.

Ключевые слова: этаноллигнин лиственницы, гидрирование, сверхкритический этанол, сульфатированные катализаторы, $\mathrm{ZrO}_{2}, 1$ \% $\mathrm{Pt} / \mathrm{ZrO}_{2}$, продукты, жидкие, газообразные.

\section{1. Введение}

Древесная биомасса является одним из перспективных возобновляемых ресурсов для производства биотоплив и химических веществ. Реализованные в промышленности технологии химической переработки древесины направлены на получение целевых продуктов преимущественно из целлюлозы, при этом лигнин остается крупнотоннажным отходом. В настоящее время разрабатываются подходы к комплексной переработке, основанные на предварительном фракционировании лигноцеллюлозной биомассы на основные компоненты - целлюлозу, гемицеллюлозы и лигнин [1-4]. Известным методом выделения лигнина является экстракция лигноцеллюлозного сырья легкокипящими органическими растворителями либо их смесями с водой при температурах $180-200{ }^{\circ} \mathrm{C}$ [5]. Получаемые органосольвентные лигнины, в отличие от традиционных технических, не содержат серу, снижающую эффективность термокаталитической переработки, и имеют высокую реакционную способность в интервале температур 250-400 ${ }^{\circ} \mathrm{C}$. 
Лигнин является трехмерным аморфным полимером, содержание которого в лигноцеллюлозной биомассе достигает 30 мас.\%. Он состоит из гваяцильных, сирингильных и гидроксифенилпропановых мономерных единиц, связанных между собой углерод-углеродными и углерод-кислородными связями. Относительное содержание различающихся по строению фенилпропановых блоков зависит от вида древесины. Лигнины хвойных пород более чем на 85 \% состоят из структур гваяцильного типа с небольшим количеством структур сирингильного и р-гидроксифенильного типа. Лигнины лиственных пород на 70 \% содержат структуры сирингильного типа и небольшое количество гваяцильных компонентов [6].

Эффективная деполимеризация лигнина может быть достигнута термической конверсией в низших алифатических спиртах, находящихся в сверхкритическом состоянии $[7,8]$. Известно, что использование сверхкритических флюидов в процессах «зеленой» химии позволяет увеличить выход экстрагируемых продуктов [8]. Выбор спиртов обусловлен тем, что значения их критических температур ниже либо близки к области оптимальных температур термической деструкции лигнина. Кроме того, биоэтанол получают в процессе гидролиза, отходом которого является гидролизный лигнин. Это обстоятельство позволяет организовать переработку лигнина на месте его образования без использования дополнительных реагентов.

Для увеличения конверсии лигнина и выхода мономерных продуктов часто используют твердые кислотные катализаторы, такие как цеолиты, а также Ni, Mo, Со и металлы платиновой группы, нанесенные на различные носители [9-11]. В работе [9] изучено влияние катализаторов $\mathrm{Pt} / \mathrm{C}, \mathrm{Pd} / \mathrm{C}, \mathrm{Ru} / \mathrm{C}$ (5 мас.\% металла), нанесенных на активированный уголь, на деполимеризацию трех технических лигнинов в среде трет-бутанола при $350{ }^{\circ} \mathrm{C}$ и начальном давлении водорода 3 МПа. Наиболее высокий выход жидких продуктов 62 мас.\% был получен в присутствии 20 мас.\% катализатора Pt/C. Эти же катализаторы в аналогичных условиях испытаны в деполимеризации лигнина Protobind 1000 [10] в низших алифатических спиртах. Максимальный выход жидких продуктов 84 мас.\% получен в присутствии 10 мас.\% катализатора $5 \% \mathrm{Pt} / \mathrm{C}$ в среде этанола. В работе [12] исследовано гидрирование этаноллигнина в присутствии 20 мас.\% катализатора $5 \% \mathrm{Pt} / \gamma-\mathrm{Al}_{2} \mathrm{O}_{3}$ в этаноле. Выход жидких продуктов составил 75 мас.\% при темпеpaтуре $260^{\circ} \mathrm{C}$.

В работе [13] крафт-лигнин (Sigma-Aldrich) подвергался деполимеризации при $350{ }^{\circ} \mathrm{C}$ в сверхкритическом этаноле при давлении водорода 3 МПа в присутствии катализаторов $\mathrm{Ru} / \mathrm{C}$ и $\mathrm{MgO} / \mathrm{ZrO}_{2}$ и их смеси. Наиболее высокий выход жидких продуктов $(82,7$ мас.\%) получен при использовании в качестве катализатора механической смеси $\mathrm{Ru} / \mathrm{C}\left(10\right.$ мас.\%) и $\mathrm{MgO} / \mathrm{ZrO}{ }_{2}$ (30 мас.\%).

Системы на основе сульфатированного диоксида циркония - наиболее сильные твердые кислоты, которые позволяют в мягких условиях проводить различные реакции превращения углеводородов и кислородсодержащих соединений. $\mathrm{Pt} / \mathrm{ZrO}_{2}$ является типичным бифункциональным катализатором, содержщим кислотные и металлические активные центры [14].

Ранее нами было исследовано термопревращение этаноллигнина осины в среде сверхкритического этанола при температуре $400{ }^{\circ} \mathrm{C}$ без использования водорода в присутствии сульфатированного диоксида циркония. Показано, что под действием этого катализатора возрастает выход этанолрастворимой фракции жидких продуктов в 1,5 раза [15]. Можно предположить,

$$
-595-
$$


что использование катализатора Pt на сульфатированном диоксиде циркония в процессе гидрирования этаноллигнина лиственницы в среде сверхкритического этанола позволит увеличить выход жидких углеводородов.

Целью настоящей работы явилось изучение влияния сульфатированных катализаторов $\mathrm{ZrO}_{2}$ и $\mathrm{Pt} / \mathrm{ZrO}_{2}$ на выход и состав продуктов в процессе гидрирования этаноллигнина лиственницы в среде сверхкритического этанола при температурах 250 и $300{ }^{\circ} \mathrm{C}$.

\section{2. Экспериментальная часть}

\section{1. Выделение этаноллигнина из древесины лиственницы}

Этаноллигнин выделяли из древесины лиственницы (Larix sibirica), содержащей (\% в расчете на массу абсолютно сухой древесины): 41,2 - целлюлозы; 28,1 - лигнина; 26,4 - гемицеллюлоз (в т.ч. арабиногалактан); 3,5 - экстрактивных веществ; 0,8 - золы; элементный состав (мас.\%): С-47,5; Н-5,7; О-46,7.

Воздушно-сухие опилки древесины лиственницы (влажность 3,6 мас.\%) измельчали на вибростенде ВР-2 до размера частиц < 1 мм и подвергали обессмоливанию по методике [16]. С этой целью опилки последовательно экстрагировали петролейным эфиром и ацетоном в аппарате Сокслета. После экстракции древесину сушили на воздухе до полного удаления ацетона. Извлечение этаноллигнина из обессмоленной древесины лиственницы осуществляли по методике, описанной ранее [17], экстракцией опилок смесью этанол-вода (60-40) с последующим осаждением холодной водой. Выход этаноллигнина составил 10,4 мас.\%, что соответствует 37,0 мас.\% от содержания лигнина Класона в исходной древесине лиственницы. Элементный состав этаноллигнина (мас.\%): С - 64,3; $\mathrm{H}-6,6 ; \mathrm{O}-29,1$.

\section{2. Получение и состав катализаторов}

Гидрирование этаноллигнина лиственницы в среде сверхкритического этанола проведено в присутствии катализаторов: сульфатированного диоксида циркония и $\mathrm{Pt} / \mathrm{ZrO}$, приготовленных в Институте проблем переработки углеводородов СО РАН (г. Омск). Сульфатированный диоксид циркония содержит $\mathrm{SO}_{4}^{-2}-5,9$ мас.\%, остальное $\mathrm{ZrO}_{2}, \mathrm{~S}_{\text {Бэт }}=110 \mathrm{M}^{2} / \Gamma, \mathrm{V}_{\text {пор }}=0,09 \mathrm{~cm}^{3} / \Gamma$. Платина нанесена на $\mathrm{ZrO}_{2}$ в количестве 1 мас.\%. Подробная методика приготовления катализаторов и их детальные характеристики приведены в $[14,18]$. Гидроксид циркония был получен путем медленного осаждения из водного раствора $1 \mathrm{M} \mathrm{ZrO}\left(\mathrm{NO}_{3}\right)_{2}$ с молярным избытком $\mathrm{NH}_{4} \mathrm{OH}$. Осадок сушили при $120^{\circ} \mathrm{C}$ и обрабатывали $2 \mathrm{M}$ раствором серной кислоты. Полученный сульфатированный материал сушили при $120^{\circ} \mathrm{C}$ и прокаливали при $650{ }^{\circ} \mathrm{C}$ в потоке воздуха. Для нанесения платины сульфатированный диоксид циркония пропитывали раствором $\mathrm{H}_{2} \mathrm{PtCl}_{6}$ из расчета достижения 1 мас.\% платины в образце катализатора. Затем образец сушили при $120^{\circ} \mathrm{C}$ и прокаливали при $450{ }^{\circ} \mathrm{C}$ в токе воздуха.

\section{3. Исследование каталитических превращений}

Процесс гидрирования этаноллигнина лиственницы проводили в автоклаве Autoclave Engineers (USA) объемом 100 мл. В реактор загружали 30 мл этанола, 3,0 г лигнина и 0,3 г катализатора. Затем автоклав герметично закрывали и трижды продували аргоном для удаления воздуха. Начальное давление водорода составляло 4 МПа. Реакцию проводили при постоянном 
перемешивании при температурах 250 и $300{ }^{\circ} \mathrm{C}$ в течение 1 ч, рабочее давление в реакторе составляло 10,0 - 13,0 МПа в зависимости от используемого катализатора. После завершения реакции газообразные продукты собирали в газометр, измеряли их объем и устанавливали состав методом газовой хроматографии (ГХ). Смесь жидких и твердых продуктов количественно выгружали из автоклава вымыванием этанолом, разделяли фильтрованием. Твердый продукт промывали этанолом до тех пор, пока растворитель не становился бесцветным. Из этанольного экстракта удаляли растворитель на роторном испарителе, продукт доводили до постоянной массы сушкой под вакуумом (1 мм рт. ст.) при комнатной температуре и определяли выход жидких продуктов по формуле 1 (мас.\%):

$$
\text { Выход жидких продуктов }=\frac{\text { масса жидких продуктов }(г)}{\text { органическая масса лигнина }(\mathrm{r})} \times 100 \% .
$$

Выход твердого остатка определяли после удаления растворителя под вакуумом (1 мм рт. ст.) и высушивания при $80{ }^{\circ} \mathrm{C}$ до постоянного веса (мас.\%):

$$
\text { Выход твердого остатка }=\frac{\text { масса твердого остатка (г)-масса катализатора }(\mathrm{r})}{\text { масса исходной навески древесины }(\mathrm{r})} \times 100 \% \text {. }
$$

Суммарный выход газообразных продуктов рассчитывали по формуле 3 (мас.\%):

$$
\text { Выход газов }=\frac{\text { масса газообразных продуктов (г) }}{\text { органическая масса лигнина (г) }} \times 100 \% .
$$

Конверсию лигнина рассчитывали по формуле 4 (мас.\%):

$$
\text { Конверсия лигнина }=\frac{\text { масса лигнина }(\text { r) }+ \text { масса катализатора }(\mathrm{r})-\text { масса твердого остатка }(\mathrm{r})}{\text { органическая масса лигнина }(\mathrm{r})} \times 100 \% \text {. }
$$

Для оценки вклада реакций конверсии этанола его каталитическое превращение изучено в аналогичных условиях без лигнина.

\section{4. Исследование продуктов превращения этанола и этаноллигнина}

Состав газообразных продуктов гидрирования этанола и этаноллигнина в сверхкритическом этаноле определяли методом ГХ на хроматографе «Кристалл 2000 М» («Хроматек», Россия) с детектором по теплопроводности. Газ-носитель гелий (расход 15 мл/мин). Температура детектора $170{ }^{\circ} \mathrm{C}$. Для анализа $\mathrm{CO}$ и $\mathrm{CH}_{4}$ использовали колонку с цеолитом $\mathrm{NaX}$ ( 3 м * 2 мм) в изотермическом режиме при температуре $60{ }^{\circ} \mathrm{C}$. Анализ $\mathrm{CO}_{2}$ и углеводородных газов проводили на колонке c Porapak Q в режиме: 1 мин $-60^{\circ} \mathrm{C}$ и далее повышение температуры до $180{ }^{\circ} \mathrm{C}$ со скоростью $10^{\circ} \mathrm{C} /$ мин. Элементный состав этаноллигнина и жидких продуктов его превращения определяли с использованием анализатора HCNS-O EAFLAS HTM 1112 («Thermo Quest»).

\section{3. Результаты и обсуждения}

В процессе некаталитического гидрирования конверсия этаноллигнина лиственницы в среде сверхкритического этанола составляет 60,4 мас.\% при температуре $250{ }^{\circ} \mathrm{C}$ и 63,1 мас.\% при $300{ }^{\circ} \mathrm{C}$ (рис. 1). В этих условиях превращение этанола не наблюдалось. В присутствии катализатора $\mathrm{ZrO}_{2}$ конверсия этаноллигнина заметно возрастает: до 84,4 мас.\% при температуре $250{ }^{\circ} \mathrm{C}$ и до 92,9 мас.\% при $300{ }^{\circ} \mathrm{C}$. Более высокую активность проявляет бифункциональный катализатор $\mathrm{Pt} / \mathrm{ZrO}_{2}$. Конверсия этаноллигнина в его присутствии достигает 92,0 мас.\% при 
температуре $250{ }^{\circ} \mathrm{C}$ и 99,6 мас.\% при $300{ }^{\circ} \mathrm{C}$. Оба катализатора не проявили активности в конверсии этанола при температуре $250{ }^{\circ} \mathrm{C}$. Однако при температуре $300{ }^{\circ} \mathrm{C}$ конверсия этанола в присутствии $\mathrm{ZrO}_{2}$ и $\mathrm{Pt} / \mathrm{ZrO}_{2}$ достигала 7,8 и 8,3 мас.\% соответственно.

В присутствии катализаторов заметно возрастает выход жидких продуктов, образующихся при гидрировании этаноллигнина при температурах 250 и $300{ }^{\circ} \mathrm{C}$ (рис. 2). Если в некаталитическом процессе их выход составляет 54,6 мас.\% при $250{ }^{\circ} \mathrm{C}$ и 62,5 мас.\% при $300{ }^{\circ} \mathrm{C}$, то для катализатора $\mathrm{ZrO}_{2}$ он возрастает до 76,9 мас.\% при температуре $250{ }^{\circ} \mathrm{C}$ и до 68,5 мас.\% при $300{ }^{\circ} \mathrm{C}$. Бифункциональный катализатор $\mathrm{Pt} / \mathrm{ZrO}_{2}$ отличается наиболее высоким выходом жидких продуктов: 86,1 мас.\% при $250{ }^{\circ} \mathrm{C}$ и 87,8 мас.\% при $300{ }^{\circ} \mathrm{C}$.

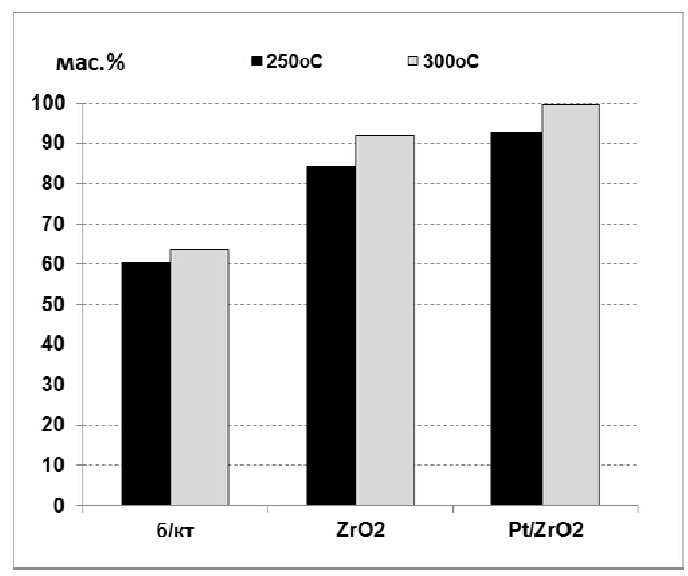

Рис. 1. Влияние катализаторов на конверсию этаноллигнина лиственницы в процессе его гидрирования в среде сверхкритического этанола при 250 и $300^{\circ} \mathrm{C}$ (мас.\%)

Fig. 1. The effect of the catalysts on the conversion of larch ethanol-lignin in supercritical ethanol at 250 and $300{ }^{\circ} \mathrm{C}$ (wt. \%)
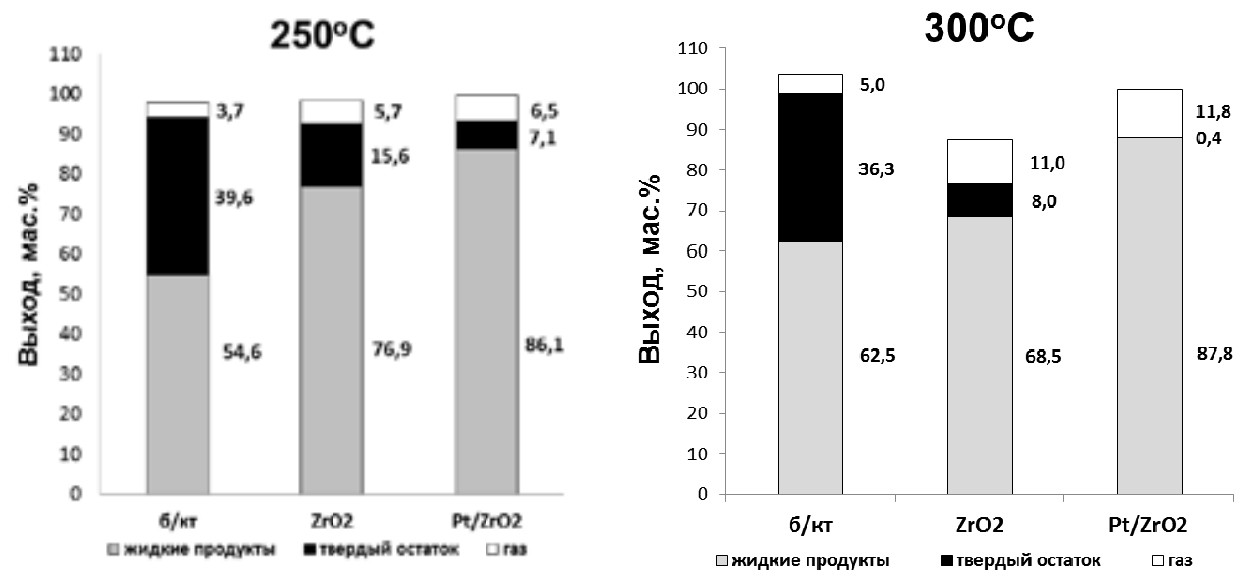

Рис. 2. Влияние катализаторов на выход продуктов гидрирования этаноллигнина лиственницы в среде сверхкритического этанола при 250 и $300^{\circ} \mathrm{C}$ (мас.\%)

Fig. 2. The effect of the catalysts on the products yield in the process of larch ethanol-lignin hydrogenation in supercritical ethanol at 250 and $300{ }^{\circ} \mathrm{C}($ wt. \%) 
Катализаторы также способствуют увеличению выхода газообразных продуктов (рис. 3). Наиболее интенсивное газообразование наблюдается в случае катализатора $\mathrm{Pt} / \mathrm{ZrO}_{2}-6,5$ мас.\% при $250{ }^{\circ} \mathrm{C}$ и 11,8 мас.\% при $300{ }^{\circ} \mathrm{C}$. Газообразные продукты состоят в основном из диоксидов углерода и метана. Они образуются при деструкции алифатических структурных фрагментов и заместителей ароматических колец лигнина $[9,10,19]$. Увеличение выхода $\mathrm{CO}$ и $\mathrm{CO}_{2}$ в присутствии катализаторов свидетельствует об интенсификации реакций деоксигенации структурных фрагментов лигнинов.

Применение катализаторов приводит к резкому снижению выходов твердого остатка. В присутствии катализаторов $\mathrm{ZrO}_{2}$ его выход уменьшается в 2,5 раза при температуре процесса $250{ }^{\circ} \mathrm{C}$ и в 4,5 раза при $300{ }^{\circ} \mathrm{C}$. При температуре $250^{\circ} \mathrm{C}$ бифункциональный катализатор $\mathrm{Pt} / \mathrm{ZrO}$ снижает выход твердого остатка в 5,6 раза по сравнению с некаталитическим процессом. При температуре процесса $300{ }^{\circ} \mathrm{C}$ в присутствии этого катализатора этаноллигнин практически полностью превращается в жидкие и газообразные продукты. Высокая конверсия этаноллигнина связана с особенностями его выделения. Известно, что органосольвентные лигнины по строению близки к нативным, так как в процессе их выделения не происходит образования большого количества новых С-С-связей, затрудняющих процесс деполимеризации $[1,20]$. В то же время металлические центры бифункционального катализатора $\mathrm{Pt} / \mathrm{ZrO}_{2}$ катализируют реакции стабилизации образующихся продуктов деполимеризации водородом в условиях процесса гидрирования.

Полученные результаты показывают, что использование бифункционального катализатора $\mathrm{Pt} / \mathrm{ZrO}_{2}$ приводит к существенной конверсии этаноллигнина лиственницы и увеличению выхода жидких и газообразных продуктов и резкому снижению выхода твердого остатка. Сравнение полученных результатов с литературными данными (табл.) показало, что при содержании платины 1 мас.\% в катализаторе $\mathrm{Pt} / \mathrm{ZrO}_{2}$ выход жидких продуктов сопоставим с выходами, полученными с использованием катализаторов с более высоким содержанием
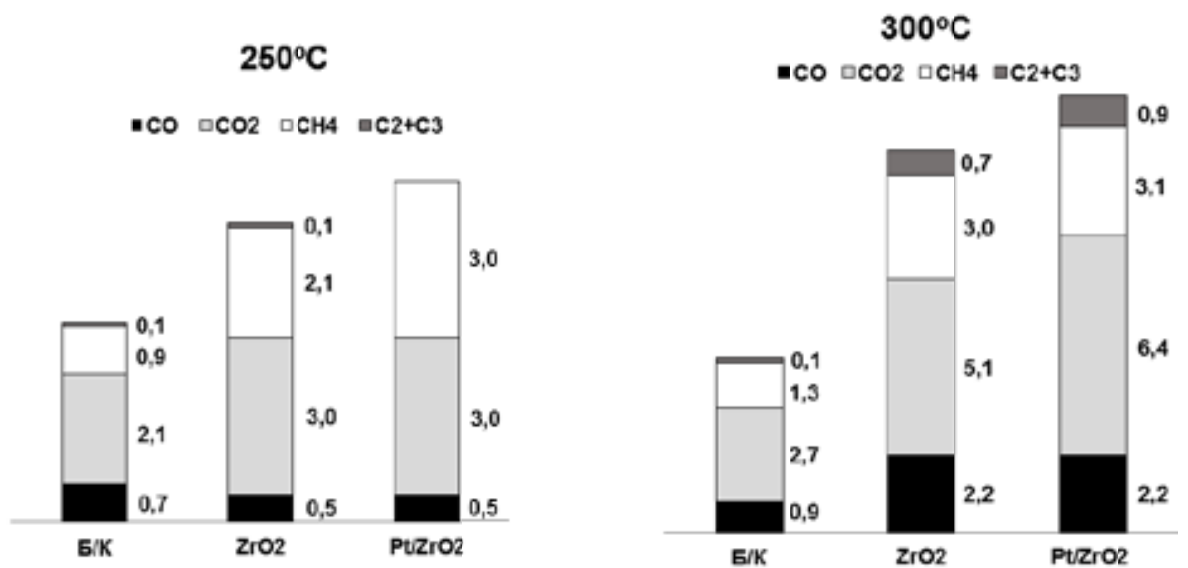

Рис. 3. Влияние катализаторов на выход газообразных продуктов гидрирования этаноллигнина лиственницы в среде сверхкритического этанола при 250 и $300{ }^{\circ} \mathrm{C}$ (мас.\%)

Fig. 3. The effect of the catalysts on the gas products yield in larch ethanol-lignin hydrogenation in supercritical ethanol at 250 and $300{ }^{\circ} \mathrm{C}$ (wt. \%) 
Таблица. Выходы жидких и твердых продуктов процессов гидрирования и гидрогенолиза лигнинов в присутствии различных катализаторов

Table. The yields of liquid and solid products in lignins hydrogenation and hydrogenolysis processes in the presence of various catalysts

\begin{tabular}{|c|c|c|c|c|c|}
\hline Лигнин & $\begin{array}{l}\text { Условия } \\
\text { процесса }\end{array}$ & Катализатор & $\begin{array}{c}\text { Выход жидких } \\
\text { продуктов, } \\
\text { мас.\% }\end{array}$ & $\begin{array}{c}\text { Выход } \\
\text { твердого } \\
\text { остатка, } \\
\text { мас.\% }\end{array}$ & $\begin{array}{c}\text { Лит. } \\
\text { источник }\end{array}$ \\
\hline Asian lignin & \multirow[t]{2}{*}{$\begin{array}{l}350^{\circ} \mathrm{C}, 3 \mathrm{MПа} \mathrm{H}_{2}, \\
40 \text { мин, } \\
\text { бутанол }\end{array}$} & $\begin{array}{c}5 \% \mathrm{Pt} / \mathrm{C}-5 \text { мас.\% } \\
10 \% \mathrm{Pt} / \mathrm{C}-10 \text { мас.\% } \\
20 \% \mathrm{Pt} / \mathrm{C}-20 \text { мас.\% } \\
5 \% \mathrm{Pd} / \mathrm{C}-5 \text { мас.\% } \\
5 \% \mathrm{Ru} / \mathrm{C}-5 \text { мас. } \%\end{array}$ & $\begin{array}{l}58 \\
60 \\
62 \\
61 \\
51\end{array}$ & $\begin{array}{c}19 \\
9 \\
11 \\
15 \\
30\end{array}$ & \multirow[t]{2}{*}{ [9] } \\
\hline $\begin{array}{l}\text { Органосольвентный } \\
\text { лигнин (тополь) }\end{array}$ & & $5 \% \mathrm{Pt} / \mathrm{C}-5$ мас.\% & 68 & 5 & \\
\hline Protobind 1000 & $\begin{array}{l}350{ }^{\circ} \mathrm{C}, 3 \mathrm{MПа} \mathrm{H}_{2} \text {, } \\
40 \text { мин, } \\
\text { этанол }\end{array}$ & $\begin{array}{l}5 \% \mathrm{Pt} / \mathrm{C}-5 \text { мас.\% } \\
5 \% \mathrm{Pd} / \mathrm{C}-5 \text { мас.\% } \\
5 \% \mathrm{Ru} / \mathrm{C}-5 \text { мас.\% } \\
10 \% \mathrm{Pt} / \mathrm{C}-5 \text { мас.\% } \\
20 \% \mathrm{Pt} / \mathrm{C}-5 \text { мас.\% }\end{array}$ & $\begin{array}{l}77 \\
78 \\
76 \\
84 \\
82\end{array}$ & $\begin{array}{l}4 \\
4 \\
8 \\
7 \\
8\end{array}$ & [10] \\
\hline $\begin{array}{l}\text { Этаноллигнин } \\
\text { (Aldrich) }\end{array}$ & $\begin{array}{l}260^{\circ} \mathrm{C}, 2 \mathrm{MПа} \mathrm{H}_{2} \text {, } \\
\text { этанол }\end{array}$ & $\begin{array}{c}20 \% \mathrm{Pt} / \gamma-\mathrm{Al}_{2} \mathrm{O}_{3}- \\
5 \text { мac. } \%\end{array}$ & 75 & 10 & {$[12]$} \\
\hline $\begin{array}{l}\text { Крафт-лигнин } \\
\text { (Aldrich) }\end{array}$ & $\begin{array}{l}350{ }^{\circ} \mathrm{C}, 3 \mathrm{MПа} \mathrm{H}_{2}, \\
60 \text { мин, } \\
\text { этанол }\end{array}$ & $\begin{array}{c}5 \% \mathrm{Ru} / \mathrm{C}+10 \% \mathrm{Mg} / \\
\mathrm{ZrO}_{2}-(10+30) \text { мас.\% } \\
5 \% \mathrm{Ru} / \mathrm{C}-10 \text { мас. } \% \\
5 \% \mathrm{Ru} / \mathrm{C}+10 \% \mathrm{Mg} / \\
\mathrm{ZrO}_{2}-(10+10) \text { мас. } \%\end{array}$ & $\begin{array}{l}77 \\
88 \\
83\end{array}$ & $\begin{array}{l}11 \\
9 \\
11\end{array}$ & [13] \\
\hline
\end{tabular}

металла (5-20 \%) и/или при более высокой температуре $[9,10,12,13]$. Отметим, что в обсуждаемых работах, в отличие от нашей, катализаторы не содержали кислотных активных центров.

Известно, что термическая деполимеризация лигнина протекает с образованием нестабильных первичных продуктов, которые могут подвергаться реакциям конденсации $[1,10$, $21,22]$. В присутствии кислотных катализаторов, содержащих $\mathrm{SO}_{4}^{2-}$-ионы, прежде всего происходит расщепление эфирных $\beta$-О-4-связей с образованием интермедиатов, которые далее трансформируются в С2-альдегидо- и С3-кетофенолы, которые участвуют в реакциях реполимеризации, приводящих к образованию конденсированных продуктов [1]. В то же время восстановительные условия инициируют первичные реакции образования метоксифенолов и небольших олигомерных фрагментов. Это происходит в результате стабилизации первичных продуктов с расщепленными $\beta$-O-4 и $\alpha$-O-4-связями и гидрогенолиза гидроксильных групп боковых цепей $[1,10,22]$.

Таким образом, кислотные центры сульфатированного носителя катализатора $\mathrm{Pt} / \mathrm{ZrO}{ }_{2}$ катализируют разрыв эфирных связей лигнина, а металлические центры катализируют стабилизацию промежуточных продуктов водородом, что приводит к увеличению выхода жидких про- 


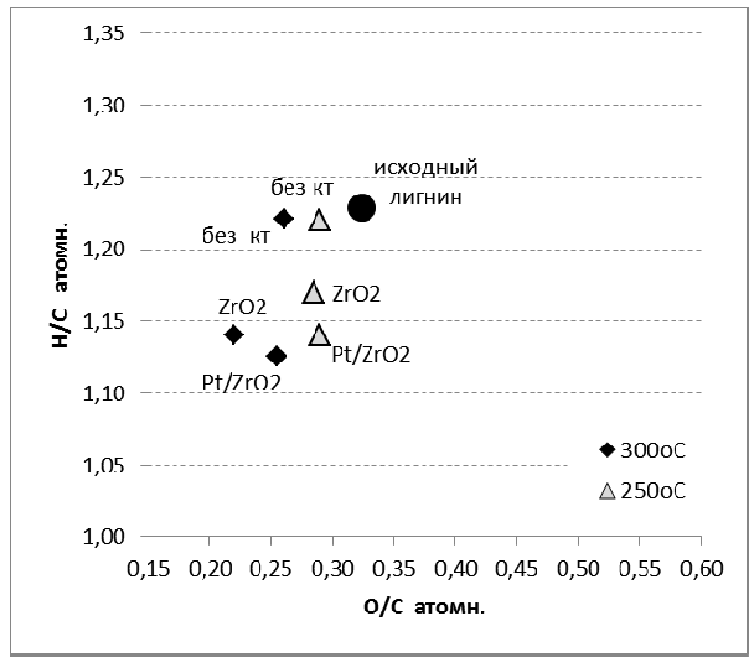

Рис. 4. Диаграмма Ван-Кревелена для жидких продуктов, полученных в результате некаталитического и каталитического гидрирования этаноллигнина лиственницы при 250 и $300{ }^{\circ} \mathrm{C}$

Fig. 4. Van Krevelen diagram of liquid products obtained by non-catalytic and catalytic hydrogenation of larch ethanol-lignin at 250 and $300^{\circ} \mathrm{C}$

дуктов и снижению образования твердого остатка, по сравнению с описанными в литературе результатами, полученными в присутствии катализаторов, содержащих только металлические центры.

Результаты исследования элементного состава показывают, что в жидких продуктах некаталитического гидрирования этаноллигнина атомное отношение $\mathrm{O} / \mathrm{C}$ ниже, чем в исходном лигнине (рис. 4). Для жидких продуктов, полученных каталитическим гидрированием этаноллигнина, наблюдается уменьшение атомного отношения как $\mathrm{O} / \mathrm{C}$, так и Н/C. Причем наиболее существенное снижение $\mathrm{O} / \mathrm{C}$ наблюдается в жидких продуктах, полученных при температуре $300{ }^{\circ} \mathrm{C}$. Наблюдаемое изменение этих отношений связывают с протеканием реакций гидрокрекинга и деоксигенации лигнина в присутствии твердых катализаторов [9].

Жидкие продукты превращения могут быть использованы для получения таких востребованных веществ, как эпоксидные смолы, пластмассы, аэрогели и т.д.

\section{Заключение}

В процессе гидрирования этаноллигнина лиственницы в среде сверхкритического этанола в присутствии катализатора кислотного типа - сульфатированного $\mathrm{ZrO}_{2}$ - конверсия лигнина достигает 84,4 мас.\% при температуре $250{ }^{\circ} \mathrm{C}$ и 92,0 мас.\% при $300{ }^{\circ} \mathrm{C}$. Использование бифункционального катализатора $\mathrm{Pt} / \mathrm{ZrO}_{2}$ приводит к увеличению конверсии этаноллигнина до 92,9 и 99,6 мас.\% соответственно при 250 и $300{ }^{\circ} \mathrm{C}$. Одновременно резко (в 5,6 раз при $\left.250{ }^{\circ} \mathrm{C}\right)$ уменьшается выход твердого остатка. В присутствии этого катализатора этаноллигнин практически полностью превращается в жидкие и газообразные продукты при температуре гидрирования $300{ }^{\circ} \mathrm{C}$.

Максимальный выход жидких продуктов - 86,0 мас.\% при температуре $250{ }^{\circ} \mathrm{C}$ и 88,0 мас.\% при $300{ }^{\circ} \mathrm{C}$ - достигается в присутствии катализатора $\mathrm{Pt} / \mathrm{ZrO}_{2}$. Использование катализаторов 
приводит к снижению в образующихся жидких продуктах атомного отношения О/С и Н/C. При этом катализаторы увеличивают в 2,2 - 2,4 раза выход оксидов углерода и метана в результате интенсификации реакции деоксигенации этаноллигнина.

Исследование выполнено за счет гранта Российского научного фонда (проект № 16-1310326).

Этаноллигнин лиственницы и жидкие продукты его гидрирования исследованы с использованием приборов Красноярского регионального центра коллективного пользования кНЦ СО РАН.

\section{Список литературы}

1. Schutyser W., Renders T., Van den Bosch S., Koelewijn S.-F., Beckham G.T., Sels B.F. Chemicals from lignin: an interplay of lignocellulose fractionation, depolymerisation and upgrading. Chemical Society Reviews. 2018. Vol. 47(3), P. 852-908.

2. Van den Bosch S., Schutyser W., Vanholme R., Driessen T., Koelewijn S.-F., Renders T., De Meester B., Huijgen W.J.J., Dehaen W., Courtin C.M., Lagrain B., Boerjanbc W., Sels B.F. Reductive lignocellulose fractionation into soluble lignin-derived phenolic monomers and dimers and processable carbohydrate pulps. Energy Environ. Sci. 2015. Vol. 8, P. 1748-1763.

3. Tarabanko V.E., Kaygorodov K.L., Skiba E.A., Tarabanko N.E., Chelbina Y.V., Baybakova O.V., Kuznetsov B.N., Djakovitch L. Processing Pine Wood into Vanillin and Glucose by Sequential Catalytic Oxidation and Enzymatic Hydrolysis. Journal of Wood Chemistry and Technology. 2017. Vol. 37, P. 43-51.

4. Kuznetsov B.N., Chesnokov N.V., Yatsenkova O.V., Sharypov V.I., Garyntseva N.V., Ivanchenko N.M., Yakovlev V.A. Green catalytic valorization of hardwood biomass into valuable chemicals with the use of solid catalysts. Wood Sci. Technol. 2017. Vol. 51, P. 1189-1208.

5. Zhang K., Pei Z., Wang D. Organic solvent pretreatment of lignocellulosic biomass for biofuels and biochemical: A review. Bioresour. Technol. 2016. Vol. 199, P. 21-33.

6. Mante O.D., Agblevor F.A. Catalytic pyrolysis for the production of refinery-ready bio-crude oils from six different biomass sources. Green Chem. 2014. Vol. 16, P. 3364-3377.

7. Tekin K., Hao N., Karagoz S., Ragauskas A.J. Ethanol: A Promising Green Solvent for the Deconstruction of Lignocellulose. Chem. Sus. Chem. 2018. Vol. 11, Р. 3559-3575.

8. Боголицын К.Г. Сверхкритические флюиды: Теория и практика. 2007. Т.2(1), С. 16. [Bogolitsyn K.G. Supercritical Fluids: Theory and Practice. 2007. Vol. 2(4), P. 16. (In Russ.)]

9. Kim J.-Y., Park J., Hwang H., Kim J K.., Song I.K., Choi J.W. Catalytic depolymerization of lignin macromolecule to alkylated phenols over various metal catalysts in supercritical tert-butanol. Journal of Analytical and Applied Pyrolysis. 2015. Vol. 113, P. 99-106.

10. Kim J.-Y., Park J., Kim U.-J., Choi J.W. Conversion of lignin to phenol-rich oil fraction under supercritical alcohols in the presence of metal catalysts. Energy \& Fuels. 2015. Vol. 29, P. 51545163.

11. Jongerius A.L., Jastrzebski R., Bruijnincx P.C., Weckhuysen B.M. CoMo sulfide-catalyzed hydrodeoxygenation of lignin model compounds: An extended reaction network for the conversion of monomeric and dimeric substrates. J. Catal. 2012. Vol. 285, P. 315-323. 
12. Patil P.T., Armbruster U., Richter M., Martin A. Heterogeneously Catalyzed Hydroprocessing of Organosolv Lignin in Sub- and Supercritical Solvents. Energy \& Fuels. 2011. Vol. 25(10), P. 47134722 .

13. Limarta S.O., Ha J.-M., Park Y.-K., Lee H., Suh D. J., Jae J. Efficient depolymerization of lignin in supercritical ethanol by a combination of metal and base catalysts. J. Ind. Eng. Chem. 2018. Vol. 57, P. 45-54.

14. Лавренов А.В., Басова И.А., Казаков М.О., Финевич В.П., Бельская О.Б., Булучевский Е.А., Дуплякин В.К. Катализаторы на основе анион-модифицированных оксидов металлов для получения экологически чистых компонентов моторных топлив. Рос. хим. ж. 2007. T. LI(4), C. 75-84. [Lavrenov A.V., Basova I.A., Kazakov M.O., Phinevich V.P., Belskaya O.B., Buluchevskii E.A., Duplyakin V.K. Catalysts based on anion-modified metal oxides for the production of environmentally friendly components of motor fuels. Rus. Chem. J. 2007. Vol. LI(4), P. 75-84. (In Russ.)]

15. Шарыпов В.И., Береговцова Н.Г., Барышников С.В., Таран О.П., Лавренов А.В., Гришечко Л.И., Агабеков В.Е., Кузнецов Б.Н. Термическая конверсия щелочного лигнина древесины осины в этаноле в присутствии сульфатированных катализаторов на основе дидиоксида циркония. Журнал СФУ. Химия. 2012. Vol. 3(5), P. 251-260. [Sharypov V.I., Beregovtsova N.G., Baryshnikov S.V., Taran O.P., Lavrenov A.V., Grishechko L.I., Agabekov V.E., Kuznetsov B.N. Thermal Conversion of Alkali Lignin of Aspen Wood in Ethanol in the Presence of Sulfated Catalysts Based on Zirconium Dioxide. Journal of Siberian Federal University. Chemistry. 2012. Vol. 3(5), P. 251-260. (In Russ.)]

16. Оболенская А.В., Ельницкая 3.П., Леонович А.А. Лабороторные работы по химии древесины и целлюлозы. Москва: Экология, 1991. С. 366. [Obolenskaya A.V., Elnitskaya Z.P., Lenovich A.A. Laboratory work on the chemistry of wood and cellulose. Moscow: Ecology, 1991. P. 366 (In Russ.)]

17. Шарыпов В.И., Береговцова Н.Г., Барышников С.В., Мирошникова А.В., Кузнецов Б.Н. Состав и термические превращения этаноллигнина, выделенного из древесины осины. Журнал СФУ. Химия. 2016. Т.9(30), С. 296-307. [Sharypov V.I., Beregovtsova N.G., Baryshnikov S.V., Miroshnikova A.V., Kuznetsov B.N. Study of composition and thermal properties of ethanol-lignin isolated from aspen wood. Journal of Siberian Federal University. Chemistry. 2016. Vol. 9(3), P. 296307. (In Russ.)].

18. Belskaya O.B., Danilova I.G., Kazakov M.O., Gulyaeva T.I., Kibis L.S., Boronin A.I., Lavrenov A.V., Likholobov V.A. Investigation of active metal species formation in Pd-promoted sulfated zirconia isomerization catalyst. Appl. Catal. A: General. 2010. Vol. 387. P. 5-12.

19. Galkin M.V., Samec J.S.M. Lignin Valorization through Catalytic Lignocellulose Fractionation: A Fundamental Platform for the Future Biorefinery. Chem. Sus. Chem. 2016. Vol. 9(13), P. 1544-1558.

20. Pandey M.P., Kim C.S. Lignin depolymerization and conversion: a review of thermochemical methods. Chem. Eng. Technol. 2011. Vol. 34, P. 29-41.

21. Bouxin F.P., Jackson S.D., Jarvis M.C. Isolation of high quality lignin as a by-product from 3 ammonia percolation pretreatment of poplar wood. Bioresour. Technol. 2014. Vol. 162, P. 236-242.

22. Bouxin F.P., Mc Veigh A., Tran F., Westwood N.J., Jarvis M.C., Jackson S.D. Catalytic depolymerisation of isolated lignins to fine chemicals using a Pt/alumina catalyst: part 1-impact of the lignin structure. Green Chem. 2015. Vol. 17, P. 1235-1242.

$$
-603-
$$

